\title{
Right ventricular architecture responsible for mechanical performance: Unifying role of ventricular septum
}

\author{
Gerald Buckberg, MD, ${ }^{a}$ and Julien I. E. Hoffman, MD $^{\mathrm{b}}$
}

The right ventricle (RV) is composed of a free wall containing a wrap-around circumferential muscle at its base and a septum composed of helical fibers that are oblique and cross each other at $60^{\circ}$ angles. This structure is defined by the helical ventricular myocardial band and defines RV function because the wrap-around transverse fibers constrict or compress to cause the bellows motion responsible for $20 \%$ of RV output, whereas the oblique fibers determine shortening and lengthening that produces $80 \%$ of RV systolic function. Clinical shortening is quantified by tricuspid annular plane systolic excursion and measured by echocardiography. Destruction of the free wall by electrocautery or patch replacement does not alter RV function if the septum is intact. Conversely, septal damage causes RV dysfunction if pulmonary vascular resistance is increased. The interaction between structure and function to cause RV failure and how these factors become corrected is defined for RV failure, RV relationship to LV failure, resynchronization, pacing, RV dysplasia, left ventricular assist device, intraoperative septal injury during myocardial protection, the septal role in tricuspid insufficiency, pharmacologic decisions on altering pulmonary vascular resistance in RV failure, congenital heart disease, and adult heart disease is considered in this overview. These structure-function relationships emphasize why clinical decisions must be based on knowledge of normality, recognizing how disease offsets normality, and introducing actions that rebuild normality. (J Thorac Cardiovasc Surg 2014;148:3166-71)

Supplemental material is available online.

Right ventricular (RV) failure is a difficult problem because its management requires recognizing structure-function relationships that are not well understood. The crescentshaped RV cavity differs from the conically shaped left ventricular (LV) cavity in several ways (Figure 1, A). The RV free wall is thin and composed of predominantly transverse fibers, with scanty trabecular subendocardial longitudinal fibers $^{1,2}$ (Figure 1, B). The ventricular septum forms its medial wall and is a midline structure that contains only oblique helical fibers that cross each other at $60^{\circ}$ angles (Figure 1, $C$ and $D$, and Figure E1). In contrast, the LV free wall is thick, and both the free wall and the septum contain helical fibers that have been confirmed by diffusion tensor magnetic resonance imaging (MRI) tractography in mammalian and human species. ${ }^{\mathrm{E} 1, \mathrm{E} 2}$ Consequently, the entire left ventricle contains helical fibers, but this architecture occurs only in the RV septum. As with the

From the Department of Cardiothoracic Surgery, ${ }^{a}$ University of California, Los Angeles, David Geffen School of Medicine, Los Angeles, Calif; and Department of Pediatrics and Cardiovascular Research Institute, ${ }^{\mathrm{b}}$ University of California, San Francisco, School of Medicine, San Francisco, Calif.

Disclosures: Gerald Buckberg reports equity ownership in Helical Heart Company. The other author has nothing to disclose with regard to commercial support.

Received for publication May 13, 2014; accepted for publication May 14, 2014; available ahead of print June 25, 2014.

Address for reprints: Gerald Buckberg, MD, Department of Cardiothoracic Surgery, University of California, Los Angeles, David Geffen School of Medicine, $10833 \mathrm{Le}$ Conte Ave, 62-258 CHS, Los Angeles, CA 90095 (E-mail: gbuckberg@mednet. ucla.edu).

$0022-5223 / \$ 36.00$

Copyright (c) 2014 by The American Association for Thoracic Surgery

http://dx.doi.org/10.1016/j.jtcvs.2014.05.044 right ventricle, the LV base (upper two thirds) contains a wrap with transverse fibers. ${ }^{2}$ Biventricular function is related to fiber orientation, because the transverse fibers, although causing circumferential strain to compress or narrow the cavity, can only account for $20 \%$ to $30 \%$ of the ejection fraction. ${ }^{3,4}$ In contrast, helical fibers cause longitudinal strain when the reciprocal oblique spirals thicken and coil, accounting for $>60 \%$ of the ejection fraction $^{3,4}$ (Figure E2).

In 1953, Rushmer and colleagues, ${ }^{3}$ with limited imaging studies, concluded that the mechanical effectiveness of the myocardial fiber layers depended on their anatomic location and orientation. More recently, insight into the function of these transverse and helical contributions has come from imaging analysis using 2- and 3-dimensional echocardiography, velocity vector imaging, MRI, and diffusion tensor $\mathrm{MRI}^{5, \mathrm{E} 1, \mathrm{E} 2}$ (Figure E3). The findings from these studies are consistent with the hypothesis that each functional motion is explicable by the Torrent-Guasp helical ventricular myocardial band model, ${ }^{2, \mathrm{E} 3}$ which shows 2 interconnected muscle bands-a basal loop with transverse fibers surrounding the left and right ventricles and an apical loop composed of a right- and left-handed helix that form an apical vortex (Figure 1, $C$ and $D$ ).

Historically, RV systole was ascribed to

1. Inward movement of the RV free wall, producing a bellows effect

2. Contraction of longitudinal fibers that draw the tricuspid annulus toward the RV apex

3. Infundibular contraction toward the end of systole

4. LV assistance to RV contraction by way of the shared interventricular septum and contiguous LV and RV circumferential fibers 


$$
\begin{aligned}
& \text { Abbreviations and Acronyms } \\
& \begin{array}{ll}
\text { LV } & =\text { left ventricular } \\
\text { MRI } & =\text { magnetic resonance imaging } \\
\text { RV } & =\text { right ventricular } \\
\text { TAPSE } & =\text { tricuspid annular plane systolic excursion }
\end{array}
\end{aligned}
$$

Rushmer and colleagues ${ }^{3}$ concluded that RV contraction was primarily caused by long-axis shortening because the midpoint width decreased minimally. Their conclusions have been confirmed by echocardiographic studies that showed minimal narrowing and that tricuspid annular plane systolic excursion (TAPSE) (Figure 2) quantifies RV displacement from the base to apex, correlates with its velocity, $\mathrm{RV}$ ejection fraction, and fractional area change, and strongly predicts the stroke volume index and hazard ratio of death after pulmonary artery hypertension. ${ }^{6}$

Nearly $80 \%$ of RV systolic ejection is associated with longitudinal shortening by TAPSE. ${ }^{6}$ The helical ventricular myocardial band model has provided mechanical explanations for these $4 \mathrm{RV}$ ejection factors:

1. Basal loop constriction causes the (minor) bellows effect

2. Longitudinal shortening develops from coiling and shortening of both arms of the helix and not from RV longitudinal muscle, which is too scanty to play a major role

3. Late infundibular contraction comes from oblique ascending fibers that are extensions of the ascending segment of the apical loop (Figure 1,D), because a delay occurs in contraction of this helical segment $t^{5, \mathrm{E} 3}$

4. No separate left- and right-sided septum is present, but rather a biventricular septum is present, with helical arms whose coiling causes longitudinal shortening ${ }^{5, \mathrm{E} 3}$

The septum is formed only by helical fibers and accounts for $\leq 40 \%$ of the ventricular muscle mass $^{7}$ (Figure 3). Functional interaction between the right and left ventricle has been termed "ventricular interdependence," or forces transmitted from 1 ventricle to the other through the myocardium and pericardium, independent of neural, humoral, and circulatory mechanisms. ${ }^{8}$ In reality, the septum is the cause of this interdependence. A series of studies have defined its seminal role in RV performance. ${ }^{8, \mathrm{E} 4}$ $\mathrm{RV}$ failure does not occur after elimination of all RV free wall muscle function after its exclusion by electrocautery, ${ }^{\mathrm{E} 5 \mathrm{E} 6}$ right coronary artery occlusion, ${ }^{\mathrm{E} 7}$ infusing the right coronary artery with glutaraldehyde, ${ }^{\mathrm{E}, \mathrm{E} 9}$ its replacement by a plastic patch, ${ }^{\mathrm{E} 10, \mathrm{E} 11}$ or its isolation and subsequent regional ventricular fibrillation. ${ }^{\text {E12 }}$ In 1 study, RV free wall ischemia by right coronary artery occlusion did not depress RV function until septal ischemia was superimposed by embolization of the septal vessels or after causing pulmonary hypertension. ${ }^{\mathrm{E}}$ These findings have characterized the septum as the "RV lion."

This newer understanding of RV structure and function explains why Lee and colleagues ${ }^{10}$ found no difference in late RV failure after conventional or limited free wall ventriculotomy in patients with tetralogy of Fallot who had pulmonary regurgitation. Before the current knowledge of the anatomy and function of the RV was available, planning RV procedures was linked to protecting a muscle (the free wall) that has little role in RV performance. Instead, future surveys must address septal function.

\section{BIVENTRICULAR FAILURE}

The saying "left ventricular failure begets right ventricular failure" is well known, and the septum is an important mediator. Increased LV end-diastolic pressure and associated pulmonary edema will cause pulmonary hypertension, and, if the septum is stretched to become dysfunctional by making the helix fibers more transverse, the RV free wall will be unable to compensate and RV failure will result. Furthermore, as the left ventricle dilates, the septum will encroach on the RV cavity. Pronounced septal bowing without any change in the architecture of the LV free wall was seen after volume loading in dogs with chronic mitral regurgitation ${ }^{11}$ (Figure 4). In some patients with aortic stenosis, Bernheim $^{\mathrm{E} 13}$ observed RV failure without pulmonary congestion and attributed this to obstruction of the RV outflow tract by the rightward displacement of the septum. Failure to find a systolic pressure gradient between the right ventricle and main pulmonary artery in these patients suggested that impaired RV filling and septal dysfunction were the mechanisms. Support for this hypothesis comes from the "reverse Bernheim effect," when closure of a large atrial septal defect restored the septum to its midline position and improved cardiac output during exercise. ${ }^{\text {E14 }}$

Septal muscular function has been described; however, normal excitation-contraction coupling is needed to remedy septal stretch. For example, cardiac resynchronization therapy returns the septum to its midline position but will fail to restore its twisting. Consequently, marginal augmentation of oxygen consumption will occur with cardiac resynchronization therapy. ${ }^{12}$

\section{RIGHT VENTRICLE}

Belief that the right ventricle is nonessential has stemmed from the absence of RV failure after excluding the free wall and the Fontan procedure, which excludes the entire RV free wall and septum. ${ }^{13, E 15}$ Each instance focuses on the conduit function of the right ventricle, but disregards the septum, which furnishes $80 \%$ of RV performance.

Septum importance became evident after recognizing the $40 \%$ clinical mortality that occurred after right 


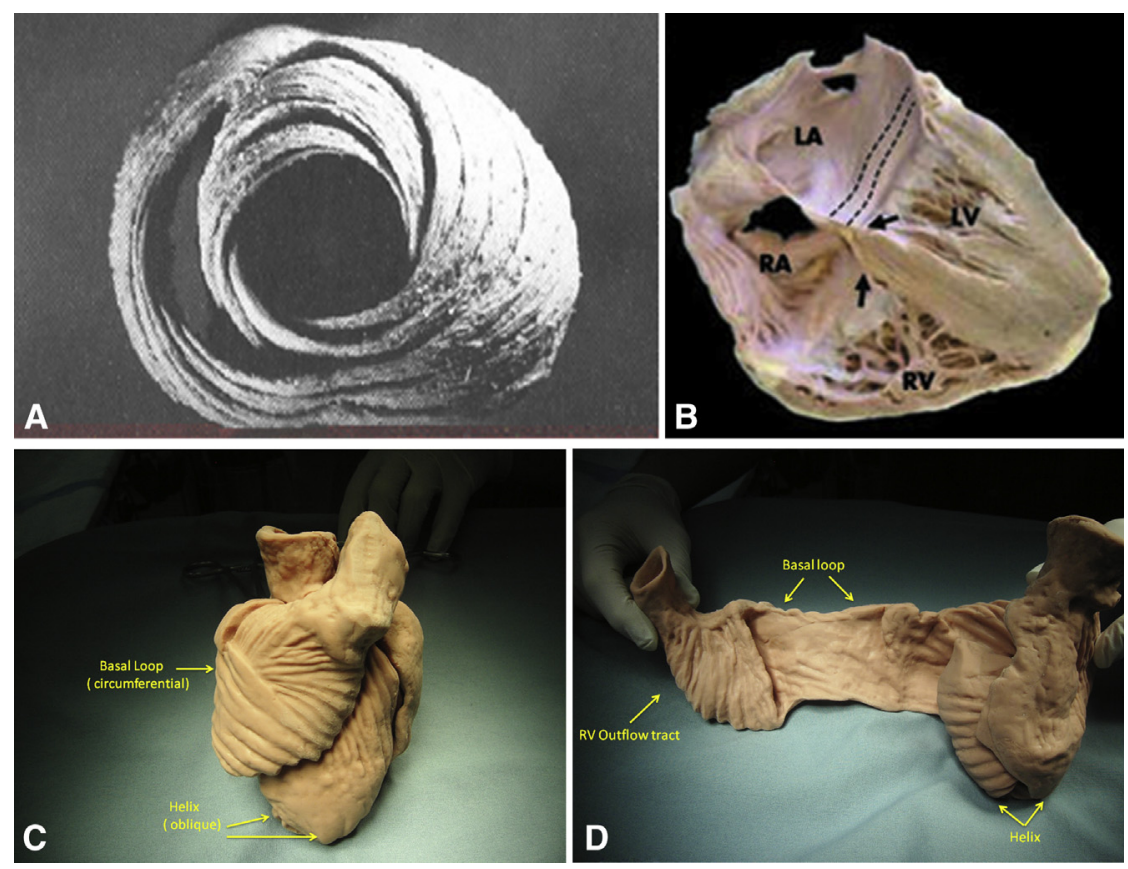

FIGURE 1. A, Cross-sectional view of both ventricles demonstrating the crescent shape of the right ventricle and conical form of the left ventricle. The obliquity of the septal muscle structure and its spiral arrangement is clear. Note the thickened septum and the wrap around basal loop. B, Longitudinal appearance of heart, showing the thin right ventricular free wall, trabecular right ventricular surface muscle, and (C) thickness of the biventricular septum. $\mathrm{C}$, View of the intact heart demonstrating the transverse appearance of the right ventricular free wall and oblique fiber arrangement of the underlying anterior segment of the apical loop that covers the right ventricular septum and lower left ventricular free wall. D, Unfolding of the basal loop containing predominantly transverse fibers and the underlying helix that comprises the left and right ventricular septum. Note the oblique fibers of the right ventricular base adjacent to the pulmonary artery and the helical formation of the septum, such that the helical fibers cross each other at $60^{\circ}$ of angulation when the heart is filled. $L A$, Left atrium; $R A$, right atrium; $L V$, left ventricle; $R V$, right ventricle.

coronary artery occlusion that also obstructed the large septal branches. ${ }^{14}$ It has also been shown by the deterioration of septal function in ischemic, nonischemic, and valvular cardiomyopathy, when the dilated ventricle has bowed the septum to the right side, causing a wall motion disorder that limits its contractile performance. In contrast, surgical ventricular restoration procedures that return the septum to its midline position and do not injure it by myocardial protection methods will recruit this large physiologic muscle mass to augment myocardial
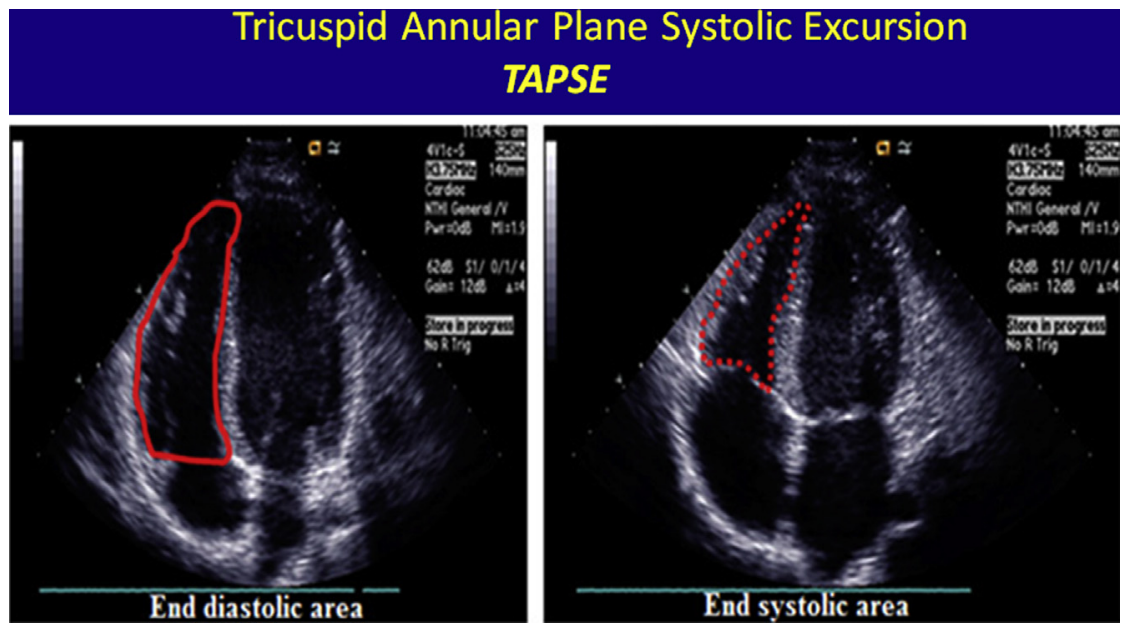

FIGURE 2. Echocardiographic appearance of tricuspid annular plane systolic excursion. Note the predominant shortening during contraction, moving this plane from the base to apex. Longitudinal shortening predominates, because transverse shortening is minimal. TAPSE, Tricuspid annular plane systolic excursion. 

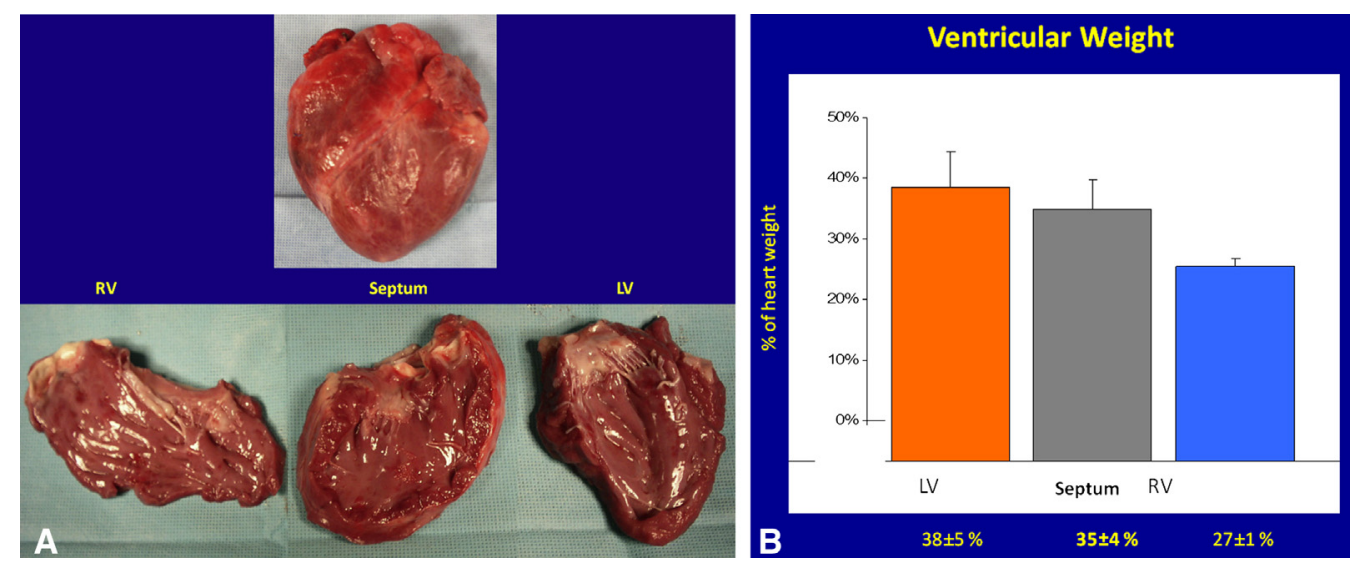

FIGURE 3. A, Ventricular myocardium separated into the right ventricle $(R V)$, septum, and left ventricle $(L V)$. Note the size of the biventricular septum muscle mass. B, Graph showing the weight of the respective segments of the LV, RV, and septum.

performance. ${ }^{15}$ The spectrum of right-sided clinical events that physiologically alter ventricular function by causing septal bowing include atrial and ventricular septal defect, pulmonary hypertension, and pulmonary insufficiency. Right-sided heart performance will improve in patients with pulmonary hypertension if septal injury has been avoided, which has been observed after medical correction of pulmonary hypertension; longitudinal shortening by TAPSE will also improve. ${ }^{6}$ This favorable effect did not occur after surgical procedures that remedied pulmonary hypertension, ${ }^{16}$ because the TAPSE remained lowered, primarily because of intraoperative septal damage. In contrast, septal restoration improved RV performance in patients with pulmonary insufficiency that had developed after tetralogy of Fallot repair using reduction of the akinetic free wall and closure of the right ventricle with a suture line that rebuilt a normal septal position, when septal damage was avoided. ${ }^{17}$

\section{RV DYSPLASIA}

In RV dysplasia, the RV free wall will be replaced by fibrosis and fat (Figure E4), the right ventricle will dilate, and right-sided heart failure and arrhythmias develop. Only $20 \%$ of patients will have septal involvement ${ }^{18}$; however, RV failure will occur because the aneurysmal free wall will dissipate some of the RV stroke volume. The pulmonary pressures can be normal; however, the septal stretch can also jeopardize its function and impair longitudinal shortening. Gadolinium MRI and biplane ventriculography can define septal viability and function and indicate where surgical correction should occur.

$\mathrm{RV}$ restoration includes surgically reducing the free wall size by partial exclusion and outflow tract closure. The treatment goals are to limit the free wall aneurysm and restore the midline septal position. Free wall shrinkage has been reported to diminish arrhythmias and improve the force of septal contractions. ${ }^{19}$

\section{Control}

Mitral Regurgitation

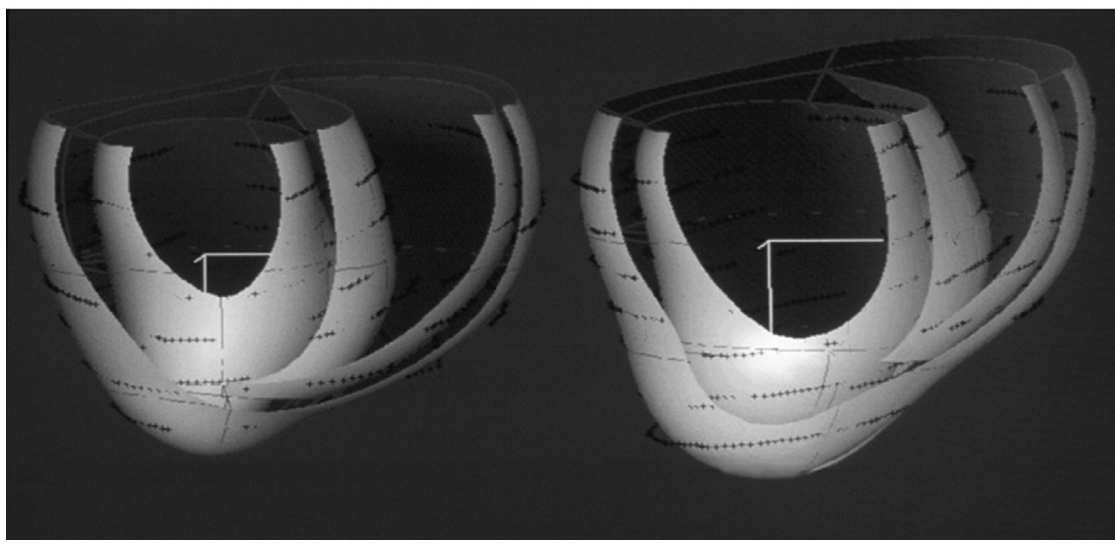

FIGURE 4. Left ventricular end-diastolic epi- and endocardial surface display of reconstructed magnetic resonance images before and 4 months after mitral insufficiency. Note the preferential bulging of the septum compared to the lateral wall during this period, as shown by Young and colleagues. ${ }^{11}$ 


\section{RV FAILURE AFTER LV ASSIST DEVICE PLACEMENT}

The importance of the septum's oblique fiber orientation has been exemplified by the RV failure that occurs after placement of an LV assist device for perioperative LV dysfunction, because adjusting the extent of LV decompression will immediately improve RV failure. ${ }^{20} \mathrm{RV}$ failure will arise in patients with an LV assist device and, initially, a low pulmonary vascular resistance, when the resistance increases progressively owing to lung endothelial injury from multiple blood and platelet transfusions. The RV free wall with transverse fibers will be unable to maintain normal RV output, the LV venous return will decrease, and the LV cavity size will decrease. This causes the septum to bulge toward the left ventricle (Figure E5), adversely altering septal fiber orientation and impairing its twisting function. This change in septal position will be apparent by echocardiography and can be reversed by reducing $\mathrm{LV}$ suction. A RV assist device will sometimes be required, especially if septal damage has occurred from inadequate myocardial protection.

Treatment of increased pulmonary vascular resistance requires vasodilators (amrinone, milrinone, nitric oxide) rather than vasoconstrictors (dopamine, epinephrine), which requires even greater septal twisting. RV failure will improve as the pulmonary vascular resistance decreases, and, despite septal damage, the RV free wall will maintain normal RV output, such that the RV assist device can be removed.

\section{CARDIAC TRANSPLANTATION}

RV failure can occur after cardiac transplantation and will be shown by high right atrial pressures. The failure has been attributed to the persistently high pulmonary vascular resistance that exists in the recipients, but most likely it has been caused by septal injury in the donor heart that diminishes its septal twisting capacity to ensure adequate lung blood flow in patients with an elevated pulmonary vascular resistance. Impaired septal twisting during transplantation can be prevented using the integrated method of myocardial protection ${ }^{21}$; it reverses injury and restores myocardial function as long as 6 hours after acute myocardial infarction. ${ }^{22}$ Novel reperfusion methods, especially with the addition of white blood cell filters, might prevent this septal damage, an injury that never existed in the healthy donor heart. The resultant normal septal performance will also reduce the prolonged use of inotropic agents or nitric oxide.

\section{CONGENITAL HEART DISEASE}

$\mathrm{RV}$ pressure and volume overload are common in children with congenital heart disease and will be accompanied by septal bulging toward the left ventricle, causing a more transverse arrangement of its helical fibers and resultant decreased septal function. Often, preoperative hypokinesia will be superimposed on the septal damage from inadequate myocardial protection, leading to early postoperative right-sided heart failure. RV failure can also develop late after repair of tetralogy of Fallot if substantial pulmonary regurgitation is present. Because the free wall contraction contributes only $\sim 20 \%$ of $\mathrm{RV}$ ejection, changes in the type of ventriculotomy in the RV outflow tract will not affect this complication, which is due to septal dysfunction. ${ }^{10}$ Novel procedures that restore septal function using an imbricating suture before implanting a new pulmonary valve might improve $\mathrm{RV}$ function. ${ }^{17}$

Septal importance has been illustrated by the results after the Fontan procedure, which excludes the entire RV free wall and septum. This procedure is contraindicated if the pulmonary vascular resistance is high. The underlying mechanism is that exclusion of the septum by the Fontan procedure offsets the requisite myocardial twisting needed to combat increased pulmonary vascular resistance.

Children with preoperative pulmonary hypertension can improve immediately after surgery that lowers the afterload; however, they might then develop RV failure if pulmonary vasospasm subsequently occurs in the intensive care unit. This complication will occur only if the septum has been damaged by inadequate myocardial protection, because its requisite twisting will be hampered.

The role of septal dysfunction has been emphasized in the treatment of children with an anomalous left coronary artery, in whom the anterior LV wall and anterior septum were dysfunctional preoperatively. Marked global dysfunction will sometimes develop when cardiopulmonary bypass is discontinued, because the superimposing septal damage from the posterior septum accounts for the hemodynamic compromise. Extracorporeal membrane oxygenation will be required, but the injury should be short-lived, with the stunning abating and biventricular function returning.

Patients with a univentricular heart have provided a clear view of the importance of the septum. Septal structure deficiency implies the absence of the myocardial fold that initiates the oblique fiber orientation that generates the twisting movement. ${ }^{23}$ Instead, the resultant circular chamber retains the more inefficient transverse fiber orientation. Resolution of this defect surgically cannot be expected, because the natural fiber orientation cannot be restored.

\section{ADULT CARDIAC SURGERY}

Intraoperative severe septal dysfunction resulting in its paradoxical movement developed in almost $50 \%$ of 3300 adult cardiac surgery patients, whose septum had been normal preoperatively. ${ }^{24}$ Lesser injuries (akinesia, severe hypokinesia) were not reported. This damage has been regarded as a usual occurrence after different cardioplegic methods. ${ }^{25}$ This abnormality will not be immediately 
apparent, and diagnosis of RV failure and its cause will be delayed. We can only see the RV free wall and can only diagnose RV failure when the RV free wall has become dilated after it has filled. This late clinical sign can be foretold by observing the septum using transesophageal echocardiography before cardiopulmonary bypass has been stopped. The septal injury can be prevented using the integrated blood cardioplegia method. ${ }^{7}$ Using that method, septal injury was absent in 119 consecutive adult patients undergoing ischemic times of 22 to 152 minutes. The barometer of myocardial protection should be septal function, and the current method should be used only if septal damage can be prevented and must be changed if it occurs.

\section{CONCLUSIONS}

$\mathrm{RV}$ function is determined by its fiber orientation, as described by the helical ventricular myocardial band model. The free wall has predominantly transverse fibers that narrow the cavity and account for $20 \%$ to $30 \%$ of the ejection fraction. However, the septum has helical fibers that twist and shorten the longitudinal axis of the right ventricle and account for $\sim 80 \%$ of RV ejection. Stretching the RV chamber will alter the helical fiber orientation to $<60^{\circ}$ and deliver less efficient function.

Normal septal position and twisting are essential for RV function, and the RV free wall plays a minor role and then only if the pulmonary vascular resistance is low. The septum constitutes $\sim 40 \%$ of the ventricular muscle mass; thus, septal dysfunction should be avoided using appropriate myocardial protection. Understanding the anatomy and physiology of the septum and RV free wall will open doors to treating RV dysplasia, RV failure due to pulmonary regurgitation, $\mathrm{RV}$ dysfunction after cardiac transplantation, and some right-sided congenital defects that affect LV function. It is incumbent on us all to develop methods that avoid septal damage during cardiac surgery.

\section{References}

1. Ho SY, Nihoyannopoulos P. Anatomy, echocardiography, and normal right ventricular dimensions. Heart. 2006;92(suppl 1):i2-13.

2. Kocica MJ, Corno AF, Carreras-Costa F, Ballester-Rodes M, Moghbel MC, Cueva $\mathrm{CN}$, et al. The helical ventricular myocardial band: global, three-dimensional, functional architecture of the ventricular myocardium. Eur J Cardiothorac Surg. 2006;29(suppl 1):S21-40.

3. Rushmer RF, Crystal DK, Wagner C. The functional anatomy of ventricular contraction. Circ Res. 1953;1:162-70.

4. Sallin EA. Fiber orientation and ejection fraction in the human left ventricle. Biophys J. 1969;9:954-64.

5. Buckberg G, Hoffman JI, Nanda NC, Coghlan C, Saleh S, Athanasuleas C. Ventricular torsion and untwisting: further insights into mechanics and timing interdependence: a viewpoint. Echocardiography. 2011;28:782-804.

6. Brown SB, Raina A, Katz D, Szerlip M, Wiegers SE, Forfia PR. Longitudinal shortening accounts for the majority of right ventricular contraction and improves after pulmonary vasodilator therapy in normal subjects and patients with pulmonary arterial hypertension. Chest. 2011;140:27-33.

7. Buckberg G, Athanasuleas C, Saleh S. Septal myocardial protection during cardiac surgery for prevention of right ventricular dysfunction. Anatol J Cardiol. 2008;8(suppl 2):108-16.

8. Santamore WP, Dell'Italia LJ. Ventricular interdependence: significant left ventricular contributions to right ventricular systolic function. Prog Cardiovasc Dis. 1998;40:289-308.

9. Buckberg GD. The ventricular septum: the lion of right ventricular function, and its impact on right ventricular restoration. Eur J Cardiothorac Surg. 2006; 29(suppl 1):S272-8.

10. Lee C, Lee CH, Kwak JG, Kim SH, Shim WS, Lee SY, et al. Does limited right ventriculotomy prevent right ventricular dilatation and dysfunction in patients who undergo transannular repair of tetralogy of Fallot? Matched comparison of magnetic resonance imaging parameters with conventional right ventriculotomy long-term after repair. J Thorac Cardiovasc Surg. 2014;147:889-95.

11. Young AA, Orr R, Smaill BH, Dell'Italia LJ. Three-dimensional changes in left and right ventricular geometry in chronic mitral regurgitation. Am J Physiol. 1996;271:H2689-700.

12. Auricchio A, Stellbrink C, Sack S, Block M, Vogt J, Bakker P, et al. Long-term clinical effect of hemodynamically optimized cardiac resynchronization therapy in patients with heart failure and ventricular conduction delay. J Am Coll Cardiol. 2002;39:2026-33.

13. Fontan F, Kirklin JW, Fernandez G, Costa F, Naftel DC, Tritto F, et al. Outcome after a "perfect" Fontan operation. Circulation. 1990;81:1520-36.

14. Bueno H, Lopez-Palop R, Bermejo J, Lopez-Sendon JL, Delcan JL. In-hospita outcome of elderly patients with acute inferior myocardial infarction and right ventricular involvement. Circulation. 1997;96:436-41.

15. Athanasuleas CL, Stanley AW Jr, Buckberg GD. Restoration of contractile function in the enlarged left ventricle by exclusion of remodeled akinetic anterior segment: surgical strategy, myocardial protection, and angiographic results. J Card Surg. 1998;13:418-28.

16. Tamborini G, Muratori M, Brusoni D, Celeste F, Maffessanti F, Caiani EG, et al. Is right ventricular systolic function reduced after cardiac surgery? A two- and three-dimensional echocardiographic study. Eur J Echocardiogr. 2009;10: 630-4.

17. Frigiola A, Giamberti A, Chessa M, Di Donato M, Abella R, Foresti S, et al Right ventricular restoration during pulmonary valve implantation in adults with congenital heart disease. Eur J Cardiothorac Surg. 2006;29(suppl 1): S279-85.

18. Basso C, Thiene G, Corrado D, Angelini A, Nava A, Valente M. Arrhythmogenic right ventricular cardiomyopathy: dysplasia, dystrophy, or myocarditis? Circulation. 1996;94:983-91.

19. Buckberg GD, Coghlan HC, Hoffman JI, Torrent-Guasp F. The structure and function of the helical heart and its buttress wrapping. VII. Critical importance of septum for right ventricular function. Semin Thorac Cardiovasc Surg. 2001; 13:402-16.

20. Neragi-Miandoab S, Goldstein D, Bello R, Michler R, D’Alessandro D. Right ventricular dysfunction following continuous flow left ventricular assist device placement in 51 patients: predicators and outcomes. J Cardiothorac Surg. 2012;7:60.

21. Buckberg GD, Beyersdorf F, Allen BS, Robertson JM. Integrated myocardia management: background and initial application. J Card Surg. 1995;10: 68-89.

22. Allen BS, Buckberg GD, Fontan FM, Kirsh MM, Popoff G, Beyersdorf F, et al Superiority of controlled surgical reperfusion versus percutaneous transluminal coronary angioplasty in acute coronary occlusion. J Thorac Cardiovasc Surg. 1993;105:864-79; discussion 79-84.

23. Buckberg GD. The structure and function of the helical heart and its buttress wrapping. II. Interface between unfolded myocardial band and evolution of primitive heart. Semin Thorac Cardiovasc Surg. 2001;13:320-32.

24. Reynolds HR, Tunick PA, Grossi EA, Dilmanian H, Colvin SB, Kronzon I Paradoxical septal motion after cardiac surgery: a review of 3292 cases. Clin Cardiol. 2007;30:621-3.

25. Chouraqui P, Rabinowitz B, Livschitz S, Horoszowsky D, Kaplinsky E, Smolinsky A. Effects of antegrade versus combined antegrade/retrograde cardioplegia on postoperative septal wall motion in patients undergoing open heart surgery. Cardiology. 1997;88:526-9. 


\section{E-References}

E1. Zhukov L, Barr AH. Heart-muscle fiber reconstruction from diffusion tensor MRI. In: Proceedings of 14th IEEE Visualization Conference (VIS'03). 2003;597-602.

E2. Sosnovik DE, Wang R, Dai G, Reese TG, Wedeen VJ. Diffusion MR tractography of the heart. J Cardiovasc Magn Reson. 2009;11:47.

E3. Buckberg G, Hoffman JI, Mahajan A, Saleh S, Coghlan C. Cardiac mechanics revisited: the relationship of cardiac architecture to ventricular function. $\mathrm{Circu}$ lation. 2008;118:2571-87.

E4. Goldstein JA, Tweddell JS, Barzilai B, Yagi Y, Jaffe AS, Cox JL. Importance of left ventricular function and systolic ventricular interaction to right ventricular performance during acute right heart ischemia. J Am Coll Cardiol. 1992;19:704-11.

E5. Starr I, Jeffers WA, Meade R Jr. The absence of conspicuous increments of venous pressure after severe damage to the right ventricle of the dog, with a discussion of the relation between clinical congestive failure and heart disease. Am Heart J. 1943;26:291-301.

E6. Kagan A. Dynamic responses of the right ventricle following extensive damage by cauterization. Circulation. 1952;5:816-23.

E7. Donald DE, Essex HE. Pressure studies after inactivation of the major portion of the canine right ventricle. Am J Physiol. 1954;176:155-61.

E8. Yamaguchi S, Li KS, Harasawa H, Santamore WP. Acute alterations in systolic ventricular interdependence-mechanical dependence of right ventricle on left

ventricle following acute alteration of right ventricular free wall. Basic Res Cardiol. 1993;88:350-61.

E9. Yaku H, Slinker BK, Bell SP, LeWinter MM. Effects of free wall ischemia and bundle branch block on systolic ventricular interaction in dog hearts. Am J Physiol. 1994;266:H1087-94.

E10. Sawatani S, Mandell G, Kusaba E, Schraut W, Cascade P, Wajszczuk WJ, et al. Ventricular performance following ablation and prosthetic replacement of right ventricular myocardium. Trans Am Soc Artific Intern Organs. 1974;20 B:629-36.

E11. Hoffman D, Sisto D, Frater RW, Nikolic SD. Left-to-right ventricular interaction with a noncontracting right ventricle. J Thorac Cardiovasc Surg. 1994; 107:1496-502.

E12. Cox JL, Bardy GH, Damiano RJ Jr, German LD, Fedor JM, Kisslo JA, et al. Right ventricular isolation procedures for nonischemic ventricular tachycardia. J Thorac Cardiovasc Surg. 1985;90:212-24.

E13. Bernheim H. Venous asystole in hypertrophy of the left heart with associated stenosis of the right ventricle. Rev Med. 1910;30:785-801.

E14. Dexter L. Atrial septal defect. Br Heart J. 1956;18:209-25.

E15. Lemler MS, Ramaciotti C, Stromberg D, Scott WA, Leonard SR. The extracardiac lateral tunnel Fontan, constructed with bovine pericardium: comparison with the extracardiac conduit Fontan. Am Heart J. 2006; $151: 928-33$ 


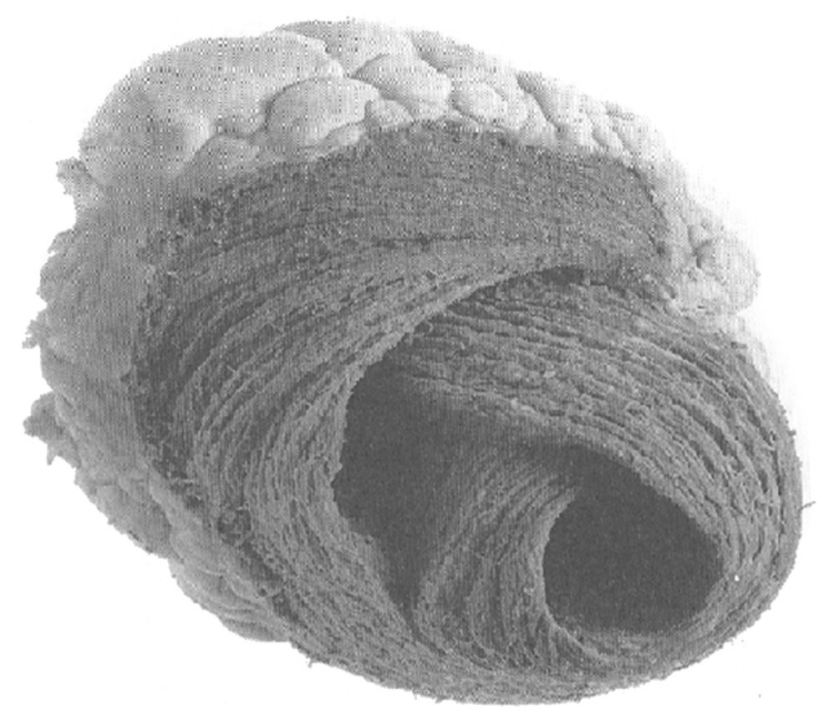

FIGURE E1. Fiber orientation relationship of the septum composed of oblique fibers that arise from the descending and ascending segments of the apical loop surrounded by the transverse muscle orientation of the basal loop that comprises the free right ventricular wall. Note the conical arrangement of the septum muscle and the basal loop wrap, forming the right ventricular cavity.

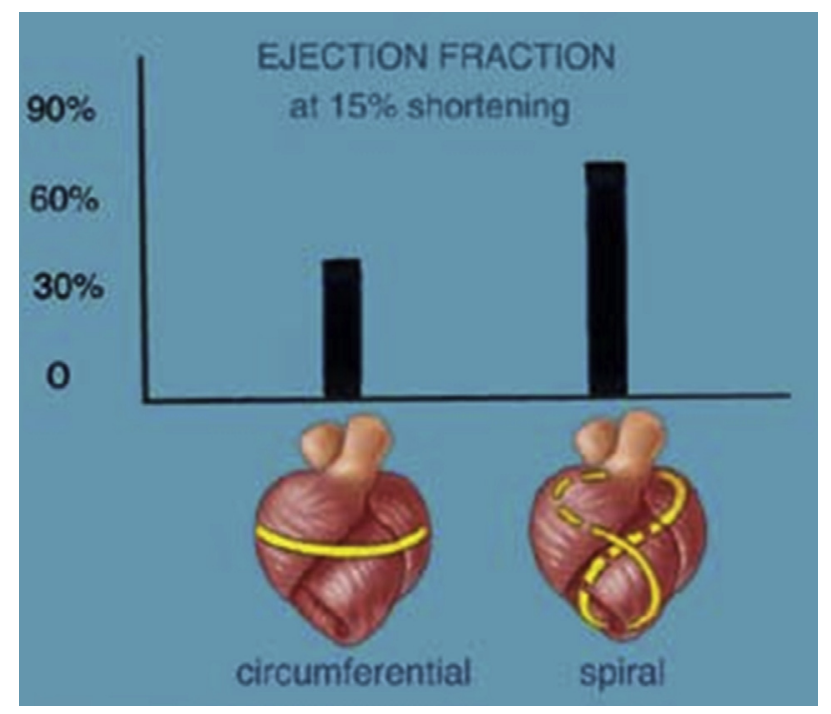

FIGURE E2. Diffusion tensor magnetic resonance image showing the helical inner or endocardial (clockwise) and outer or epicardial (counterclockwise) fiber orientation (purple and blue) and a central left ventricular free wall in the top chamber, which is white to reflect a more horizontal or very small angle pitch; these transverse fibers do not involve the septum. 


\section{Diffusion Tensor MRI}

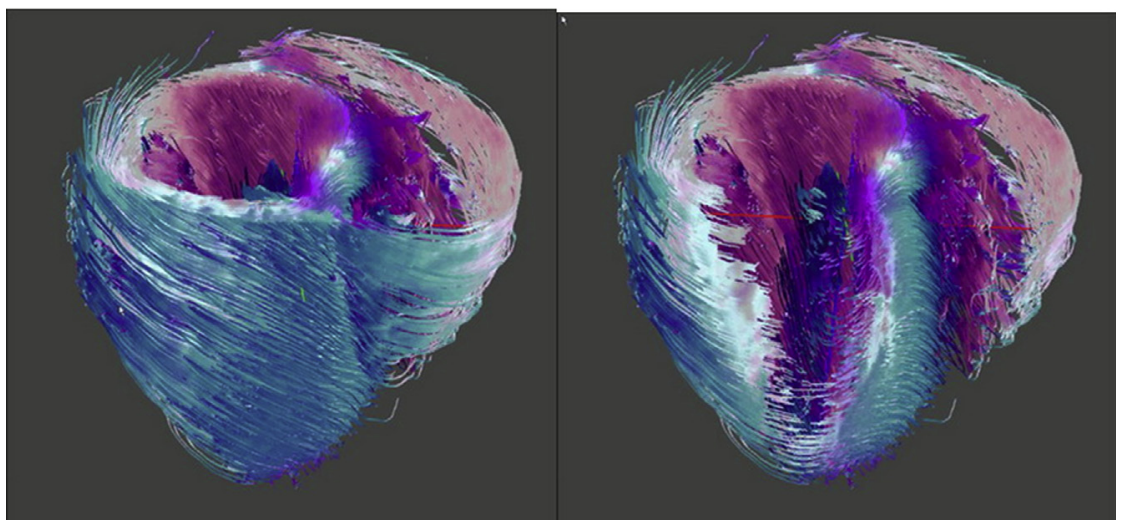

FIGURE E3. Relationship between fiber orientation and ejection fraction. Note the $30 \%$ ejection fraction that occurs when a transverse or circumferential horizontal arrangement is present compared with the $60 \%$ ejection fraction when a spiral or helical relationship is present. MRI, Magnetic resonance imaging. Reprinted with permission from Zhukov and Barr. ${ }^{\mathrm{E} 1}$

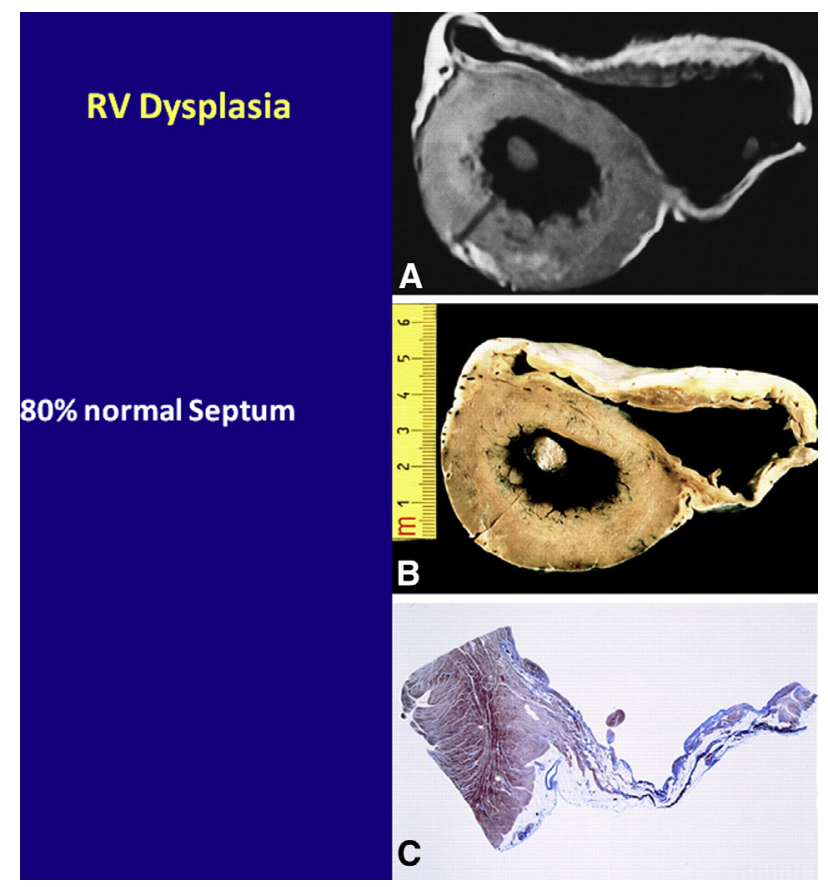

FIGURE E4. Right ventricular $(R V)$ dysplasia observed by (A) magnetic resonance image displaying whitish $R V$ free wall, with anterior and inferior aneurysm, and normal septum; (B) cross-section of heart specimen showing free wall aneurysm; and (C) histologic specimen showing free wall thinning, fibro fatty replacement, and normal septum. Reprinted with permission from Basso and colleagues. ${ }^{18}$ 
Pre op LVAD

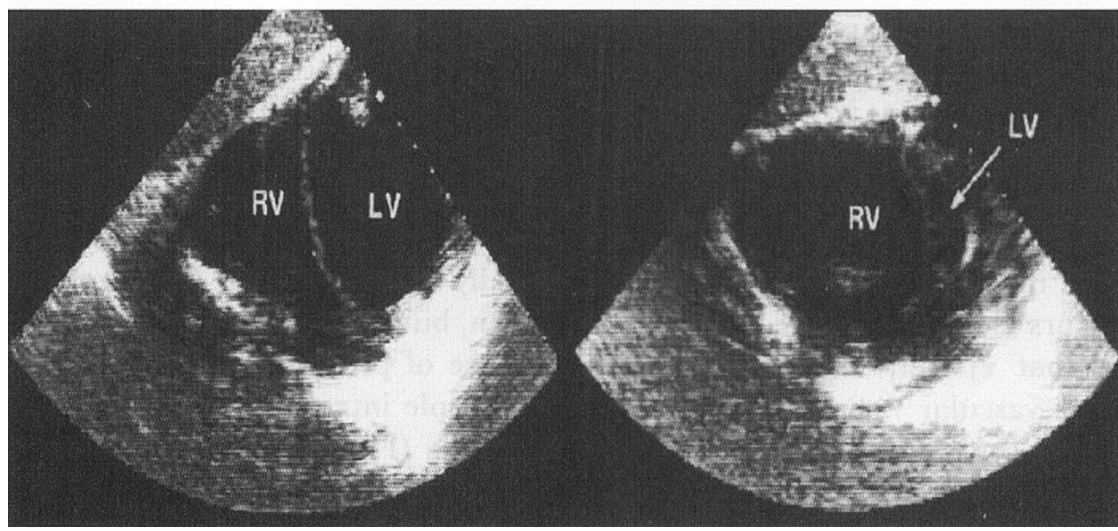

FIGURE E5. Echocardiographic view of a failing left ventricle, left, before and, right, after left ventricular decompression, as described by Robert Kormos (personal communication). Left, The thin stretched akinetic septum has been pushed or bowed into the right ventricular chamber by the distended left ventricle $(L V)$. Right, Note how the thickened septum after near total left ventricular decompression has become bowed into the left side by the distended right ventricle $(R V)$. LVAD, Left ventricular assist device. 